\title{
MULTIDETECTOR CT ANGIOGRAPHY V/S COLOUR DOPPLER ULTRASONOGRAPHY IN THE DIAGNOSIS OF PERIPHERAL ARTERIAL DISEASES OF LOWER EXTREMITIES
}

\author{
Rezia Udinoor Peedikayil1, Vadakooth Raman Rajendran², Saanida Monthampally33, Juvaina Puthiyakam \\ 1 Junior Resident, Department of Radiodiagnosis, Government Medical College, Kozhikode. \\ 2 Professor and HOD, Department of Radiodiagnosis, Government Medical College, Kozhikode. \\ ${ }^{3}$ Assistant Professor, Department of Radiodiagnosis, Government Medical College, Kozhikode. \\ ${ }^{4}$ Assistant Professor, Department of Radiodiagnosis, Government Medical College, Kozhikode.
}

\begin{abstract}
CONTEXT

Peripheral arterial disease of the lower extremity is an important cause of morbidity and affects 10 million people in India.

AIMS AND OBJECTIVES

The aims of this study were to assess the colour Doppler ultrasonography findings of lower limbs in patients with peripheral arterial disease by studying the spectral flow pattern and peak systolic velocity and also to assess the severity of stenosis and correlation of severity of stenosis on USG Doppler and MDCT angiography.
\end{abstract}

\section{MATERIALS AND METHODS}

The study included 29 patients attending surgery, Ortho OPD Government Medical College of Calicut with signs and symptoms of peripheral arterial diseases of lower limbs from January 2014 to October 2015 who underwent colour Doppler ultrasonography and MDCT angiography to know the severity of peripheral arterial diseases of lower extremities and to compare various grades of stenosis by studying the spectral flow patterns in colour Doppler ultrasonography and contrast opacification and diameter reduction in MDCT angiography.

\section{RESULTS}

In our study, 29 patients with intermittent claudication, numbness, and pain in the legs were selected. Majority of the patients were males and below 50 yrs. In our study, detection of totally occluded segments were better in MDCT angiography on comparing with Doppler USG. Most of the arteries showed good total agreement between Doppler and MDCT angiography. Aortoiliac group of vessels showed more than 80\% total agreement between Doppler and MDCT angiography. Femoropopliteal group vessels showed more than $75 \%$ total agreement. Infrapopliteal group of vessels showed more than $50 \%$ total agreement.

\section{CONCLUSION}

MDCT angiography is more sensitive in detecting lesions of suprapopliteal group of vessels and also lesions with total occlusion of the lumen in comparison to Doppler ultrasonography. Imaging plays an important role in the management of the patients with peripheral arterial disease. Due to the limitations of the Doppler ultrasound, CT angiography is used prior to any vascular intervention is required in peripheral arterial diseases.

\section{KEYWORDS}

MDCT Angiography, Colour Doppler Ultrasonography, Peripheral Arterial Disease.

HOW TO CITE THIS ARTICLE: Peedikayil RU, Rajendran VR, Monthampally S, et al. Multidetector ct angiography v/s colour doppler ultrasonography in the diagnosis of peripheral arterial diseases of lower extremities. J. Evolution Med. Dent. Sci. 2016;5(63):44574461, DOI: $10.14260 /$ jemds/2016/1017

\section{INTRODUCTION \\ Peripheral arterial disease is defined as a clinical disorder in which there is a stenosis or occlusion of aorta or arteries of the limbs. ${ }^{1}$ The disorder affects lower limbs eight times more than upper limbs. ${ }^{2}$ It is going to be a major health problem in our country due to change of the lifestyle of Indian population. The disease may manifest as claudication, rest pain, local tissue loss (Ulceration), or gangrene. ${ }^{3}$ The lower limb ischaemia presents as two distinct clinical entities: intermittent}

Financial or Other, Competing Interest: None.

Submission 21-05-2016, Peer Review 22-07-2016,

Acceptance 28-07-2016, Published 06-08-2016.

Corresponding Author:

Dr. Rezia Udinoor Peedikayil,

'Bahaar', Kommeri P.O,

Calicut - 673007,

Kerala, India.

Chennai-600010.

E-mail:drreziaup@gmail.com

DOI: $10.14260 /$ jemds/2016/1017 claudication and critical limb ischaemia. ${ }^{4}$ The most common symptom is intermittent claudication defined as pain, numbness, or a sense of fatigue in the muscles, which is increased by exercise and relieved by rest. Critical lower limb ischaemia is defined as rest pain (night pain), tissue loss (Ulceration or gangrene) lasting for more than 2 weeks, presence of ankle blood pressure of less than $50 \mathrm{mmHg}$. Critical limb ischaemia is mainly due to multi-segment plaque whereas intermittent claudication is due to single segment plaque.5,6

Noninvasive imaging modalities. ${ }^{7}$ are Doppler ultrasonography, magnetic resonance angiography, MDCT angiography, and conventional arteriography. The gold standard of investigation in peripheral arterial disease is conventional arteriography, but it does not estimate the haemodynamic significance of obstructive lesions. Colour Doppler ultrasonography is easily accessible, inexpensive, no radiation exposure, and no contrast is needed. But, it is less 
accurate in aortoiliac region, in obese patients due to increased bowel gas and limited sensitivity for multilevel stenosis. CT angiography is increasingly attractive because of the complete coverage of the lower extremity arteries. Imaging of inflow and run off arteries is possible with one acquisition using a single contrast bolus in MDCT angiography. MDCT angiography leads to adequate decision making for treatment recommendations concerning both the anatomical level of stenosis and the technique of revascularisation. This is only a comparative study as we were not able to do conventional arteriography, which is the gold standard of investigation for peripheral arterial diseases. In our study, we try to compare various grades of stenosis by studying the spectral flow patterns in colour Doppler ultrasonography and contrast opacification and diameter reduction in MDCT angiography.

\section{AIMS AND OBJECTIVES}

1. To assess the colour Doppler ultrasonography findings of lower limbs in patients with peripheral arterial disease by studying the spectral flow pattern and peak systolic velocity and also to assess the severity of stenosis.

2. To compare the colour Doppler ultrasonography findings with MDCT angiography in patients with peripheral arterial disease of lower extremity.

3. Correlation of severity of stenosis on USG Doppler and MDCT angiography.

\section{METHODS}

\section{Study Design}

Diagnostic test evaluation.

\section{Study Setting}

Cases coming to Surgical, Ortho OPD, Govt. Medical College, Kozhikode, Kerala, India.

\section{Study Period}

Jan. 2014 to Sept. 2015.

\section{Inclusion Criteria}

Patients with peripheral arterial diseases.

- Age more than 35 yrs.

- Painful cramps in the thigh and calf muscles.

- Numbness or weakness in lower limbs.

- Patients with ulcers or gangrene in lower limbs.

- Patients with feeble or absent pulses in lower limbs.

\section{Exclusion Criteria}

- Trauma patients.

- Patients with renal impairment.

\section{Sample Size}

29 patients.

\section{Study Method}

Patients were subjected to colour Doppler ultrasonography and MDCT angiography. Ultrasonography - In the grey scale system, luminal narrowing, irregularity, calcification, any atheromatous changes of vessel wall were assessed. Ultrasound evaluation was done by using $2.5 \mathrm{MHz}$ transducer from aortic bifurcation till external iliac arteries.

Femoral and other lower limb arteries were evaluated by using 7.5 MHz transducer. During Doppler ultrasonography, grading of stenosis was done by mainly based on spectral flow patterns and peak systolic velocity. Following Doppler ultrasonography, patients were subjected to MDCT angiography with 16 slice scanner (Siemens).

The anatomic coverage extends from the T11 vertebral body proximally to the feet distally.

300 to $350 \mathrm{mg}$ ( $100 \mathrm{~mL}$ ) of non-ionic contrast media was injected through antecubital vein using pressure injector at a rate of $3.5 \mathrm{~mL} /$ second through $20 \mathrm{G}$ IV cannula. Initial slice thickness was $6 \mathrm{~mm}$ and axial reconstruction has been done at $0.5 \mathrm{~mm}$ interval of $1 \mathrm{~mm}$ thickness and in coronal and sagittal sections at $2 \mathrm{~mm}$ thickness.

Images were analysed for the presence of plaque, extent and pattern of luminal narrowing, and collateral flow. Volume rendering and maximum intensity projection images were obtained from raw images from all the cases. Images were analysed for calcification, wall thickening, extent pattern of luminal narrowing, and the collateral flow. In MDCT angiography, grading was done mainly based on diameter reduction better assessed in axial images and contrast opacification.

\section{Statistical Analysis}

Various grades of stenosis in Doppler and MDCT angiography were compared and analysed with the help of SPSS 13 and charts and kappa value. The chance agreement (Kappa value) was calculated.

\begin{tabular}{|c|c|}
\hline Classification & Features \\
\hline $\begin{array}{l}\text { Normal } \\
\text { Grade } 0\end{array}$ & $\begin{array}{l}\text { Triphasic waveform; no spectral } \\
\text { broadening }\end{array}$ \\
\hline $\begin{array}{l}1 \%-19 \% \\
\text { diameter }\end{array}$ & $\begin{array}{l}\text { Triphasic waveform with minimal } \\
\text { spectral broadening }\end{array}$ \\
\hline $\begin{array}{c}20 \%-49 \% \\
\text { diameter } \\
\text { reduction } \\
\text { Grade } 2\end{array}$ & $\begin{array}{l}\text { Triphasic waveform usually maintained, } \\
\text { although reverse flow component may be } \\
\text { diminished; spectral broadening is } \\
\text { prominent with filling in of clear area } \\
\text { under the systolic peak; peak systolic } \\
\text { velocity is increased from } 30 \%-100 \% \\
\text { relative to the adjacent proximal } \\
\text { segment. } \\
\text { Proximal and distal waveforms remain } \\
\text { normal. }\end{array}$ \\
\hline $\begin{array}{c}50 \%-99 \% \\
\text { diameter } \\
\text { reduction } \\
\text { Grade } 3\end{array}$ & $\begin{array}{l}\text { Monophasic waveform with loss of } \\
\text { reverse flow component and forward } \\
\text { flow throughout cardiac cycle; extensive } \\
\text { spectral broadening; peak systolic } \\
\text { velocity is increased }>100 \% \text { relative to } \\
\text { adjacent proximal segment; distal } \\
\text { waveform is monophasic with reduced } \\
\text { systolic velocity }\end{array}$ \\
\hline $\begin{array}{l}\text { Occlusion } \\
\text { Grade } 4\end{array}$ & $\begin{array}{l}\text { No flow detected within imaged arterial } \\
\text { segment; reocclusive "thump" maybe } \\
\text { heard just proximal to site of occlusion; } \\
\text { distal waveforms are monophasic with } \\
\text { reduced systolic velocities }\end{array}$ \\
\hline \multicolumn{2}{|c|}{$\begin{array}{l}\text { Table 1: Criteria for Classifying Peripheral Artery } \\
\text { Lesions. }\end{array}$} \\
\hline
\end{tabular}




\section{Ethics}

The study was approved by the institutional research committee and ethics committee of Government Medical College, Kozhikode, Kerala, India.

\section{Statistics}

Interobserver agreement was determined by calculating a weighted kappa (Kw) statistic, which takes the degree of disagreement into account and accounts for differences in the importance of disagreement. The $\mathrm{K}$ statistic indicates the agreement beyond chance. Strength of agreement can be interpreted as poor $(\mathrm{K}<0.20)$, fair $(\mathrm{K}=0.21$ to 0.40$)$, moderate $(\mathrm{K}=0.41$ to 0.60$)$, good $(\mathrm{K}=0.61$ to 0.80$)$, or excellent $(\mathrm{K}=0.81$ to 1.0$).{ }^{9}$ In the case where the kappa cannot be calculated, the total agreement between Doppler USG and MDCT angiography was taken.

\section{RESULTS}

Twenty nine patients with intermittent claudication were subjected to Doppler ultrasonography and followed by MDCT angiography.

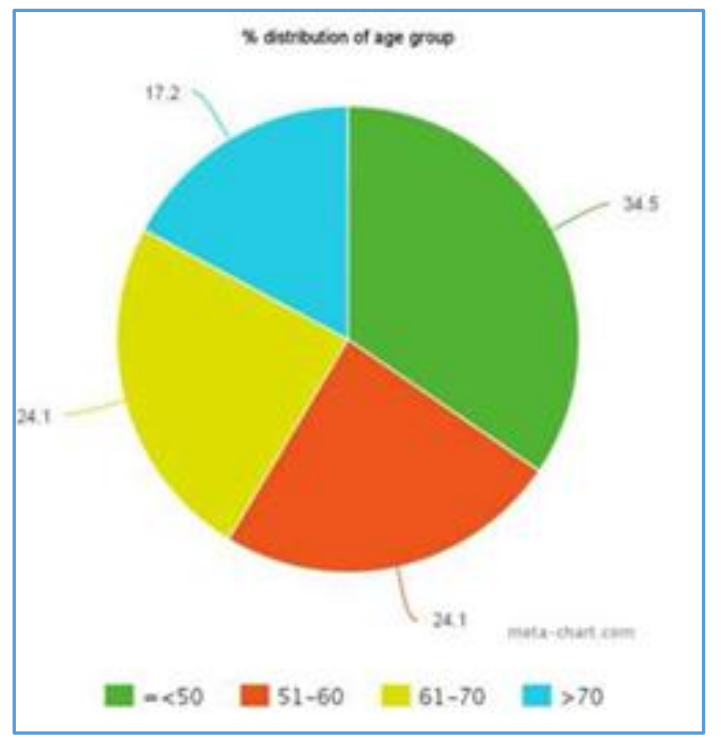

Fig. 1: Showing Frequency Distribution of the Study Group According to Age in Years

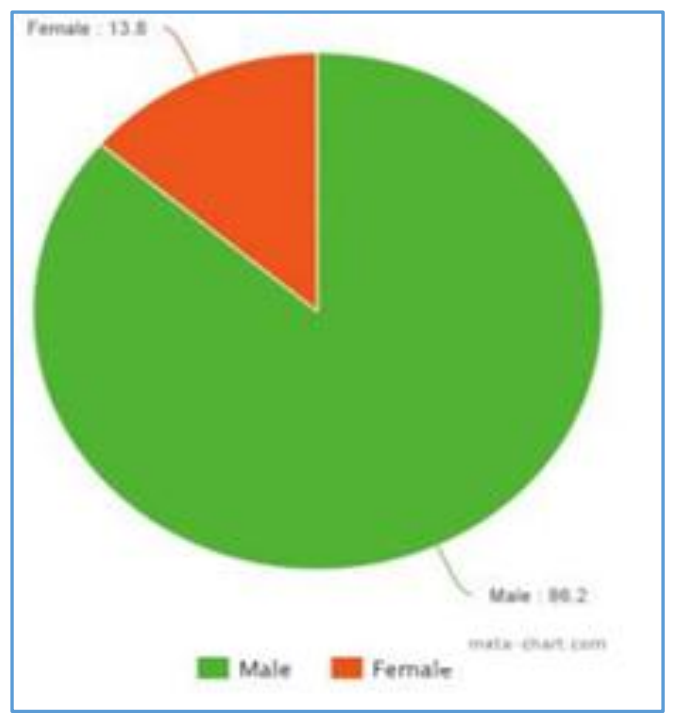

Fig. 2: Frequency Distribution of Sex in the Study Group in Peripheral Arterial Diseases

\begin{tabular}{|c|c|c|}
\hline Group of Vessels & Doppler & $\begin{array}{c}\text { MDCT } \\
\text { Angiography }\end{array}$ \\
\hline $\begin{array}{c}\text { Aortoiliac group } \\
\text { vessels }\end{array}$ & $1.5 \%$ & $2.4 \%$ \\
\hline $\begin{array}{c}\text { Femoropopliteal } \\
\text { group }\end{array}$ & $3.1 \%$ & $4.5 \%$ \\
\hline Infrapopliteal group & $4.84 \%$ & $8.17 \%$ \\
\hline Table 2: Comparison of Cases Detected by Doppler USG \\
and MDCT Angiography
\end{tabular}

\begin{tabular}{|c|c|c|}
\hline Group of Vessels & Doppler & $\begin{array}{c}\text { MDCT } \\
\text { Angiography }\end{array}$ \\
\hline Aortoiliac group & 0.9 & 0.45 \\
\hline $\begin{array}{c}\text { Femoropopliteal } \\
\text { group }\end{array}$ & 3.6 & 2.1 \\
\hline Infrapopliteal group & 6.6 & 5.3 \\
\hline \multicolumn{2}{|c|}{$\begin{array}{r}\text { Table 3: Comparison of Cases Detected by Doppler USG } \\
\text { and MDCT Angiography in Grade 2 Stenosis }\end{array}$} \\
\hline
\end{tabular}

\begin{tabular}{|c|c|c|}
\hline Group of Vessels & Doppler & $\begin{array}{c}\text { MDCT } \\
\text { Angiography }\end{array}$ \\
\hline Aortoiliac group & $0.15 \%$ & $0.15 \%$ \\
\hline $\begin{array}{c}\text { Femoropopliteal } \\
\text { group }\end{array}$ & $1.5 \%$ & $0.45 \%$ \\
\hline Infrapopliteal group & $4.2 \%$ & $1.36 \%$ \\
\hline $\begin{array}{c}\text { Table 4: Comparison of Cases Detected by Doppler USG } \\
\text { and MDCT Angiography in Grade 3 Stenosis }\end{array}$ \\
\hline
\end{tabular}

\begin{tabular}{|c|c|c|}
\hline Group of Vessels & Doppler & MDCT Angiography \\
\hline Aortoiliac group & $2.57 \%$ & $2.7 \%$ \\
\hline $\begin{array}{c}\text { Femoropopliteal } \\
\text { group }\end{array}$ & $6.35 \%$ & $7.4 \%$ \\
\hline $\begin{array}{c}\text { Infrapopliteal } \\
\text { group }\end{array}$ & $5.3 \%$ & $5.1 \%$ \\
\hline $\begin{array}{c}\text { Table 5: Comparison of Cases Detected by Doppler USG } \\
\text { and MDCT Angiography in Grade 4 Stenosis }\end{array}$ \\
\hline
\end{tabular}

\section{DISCUSSION}

In our study, 29 patients with intermittent claudication, numbness, and pain in the legs were selected.

\section{Age Distribution}

In our study, maximum number of patients were below $50 \mathrm{yrs}$. In a study by Rahul et al, 10 out of 30 patients, 10 belonged to $61-70$ yrs. age group (33.3\%), 9 patients - 51-60 yrs. (30\%), 2 - less than 40 yrs. (13.3\%). This is in comparison to study done by Cossman et al ${ }^{11}$ i.e. - 17/30 patients belonged to 61-80 yrs. There is a mismatch in our study because of small sample size.

\section{Sex Distribution}

In our study, maximum number of cases were among males. This is in comparison to the study done by Hughson et al. In their study, they found that $80 \%$ patients were males.

\section{Imaging}

Most of the arteries showed good total agreement between Doppler and MDCT angiography. Out of 23 groups of arteries, 9 showed excellent total agreement, 11 showed good agreement, 3 showed moderate agreement, and only one showed fair agreement.

Aortoiliac group of vessels showed more than $80 \%$ total agreement between Doppler and MDCT angiography. Femoropopliteal group vessels showed more than $75 \%$ total 
agreement. Infrapopliteal group of vessels showed more than $50 \%$ total agreement.

Kayhan et al $^{12}$ compared the efficacy of MDCT angiography and duplex ultrasonography to diagnose peripheral arterial occlusive disease. In their study, forty three patients with 774 segments in patients with intermittent claudication and leg pain diagnosed as mild peripheral arterial disease had undergone Doppler USG followed by MDCT angiography of lower limbs. MDCT angiography detected obstructed or stenotic lesions in $16.8 \%$ of arteries. In our study, we also found that MDCT angiography was significantly better than colour Doppler ultrasonography for detecting haemodynamically significant stenosis in the lower limb arterial system.

In our study, MDCT angiography has detected more lesions in grade 1 and 4 stenosis and Doppler USG has detected more lesions in grade 2 and 3 stenosis. In the case of infrapopliteal group of arteries, MDCT angiography has detected more lesions in grade 1 and 4 stenosis compared to suprapopliteal group of arteries. This is in comparison to study Kayhan et al 12. In their study, 774 segments of vessels were imaged by Doppler USG and MDCT angiography. MDCT angiography detected obstructed or stenotic lesions in $16.8 \%$ of arteries versus $11.1 \%$ compared to Doppler USG.

\begin{tabular}{|c|c|c|c|c|}
\hline & \multicolumn{2}{|c|}{ Kayhan A et al } & \multicolumn{2}{c|}{ Present study } \\
\cline { 2 - 5 } & Doppler & MDCTA & Doppler & MDCTA \\
\hline $\begin{array}{c}\text { Suprapopliteal } \\
\text { Group }\end{array}$ & $11 \%$ & $15 \%$ & $31.3 \%$ & $34.5 \%$ \\
\hline $\begin{array}{c}\text { Infrapopliteal } \\
\text { group }\end{array}$ & $19.6 \%$ & $11.3 \%$ & $21 \%$ & $19.6 \%$ \\
\hline
\end{tabular}

Table 6: Comparison of Frequency Distribution of Stenotic or Occluded Lesions in - Various Studies

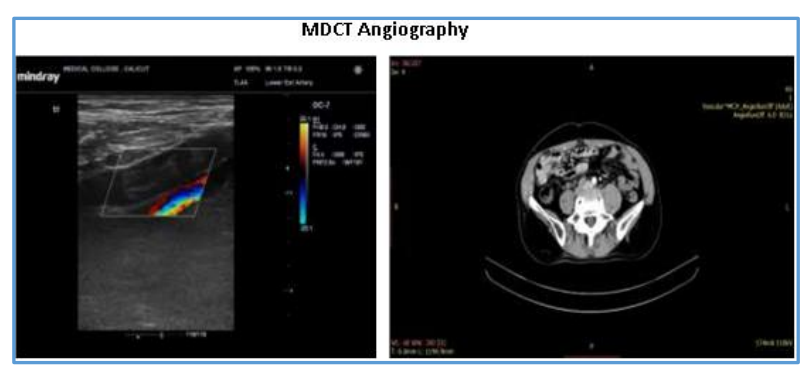

Fig. 3: Showing Total Occlusion of Right Common Iliac Artery in Doppler and MDCT Angiography

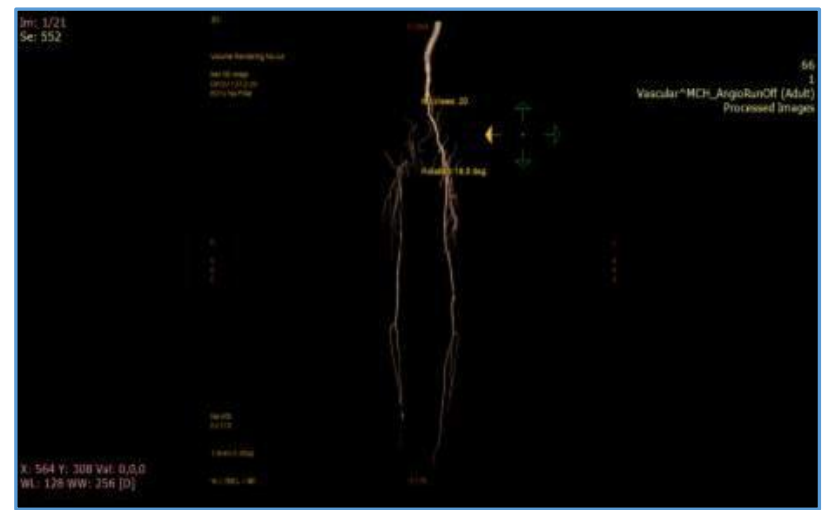

Fig. 4: Total Occlusion of Right Common Iliac Artery in MDCT Angiography

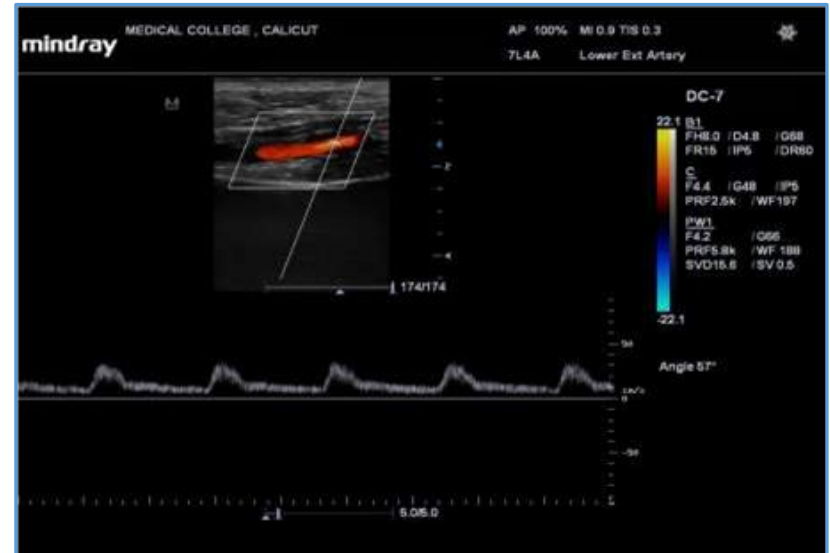

Fig. 5: Spectral Wave Pattern Distal to the Occlusion

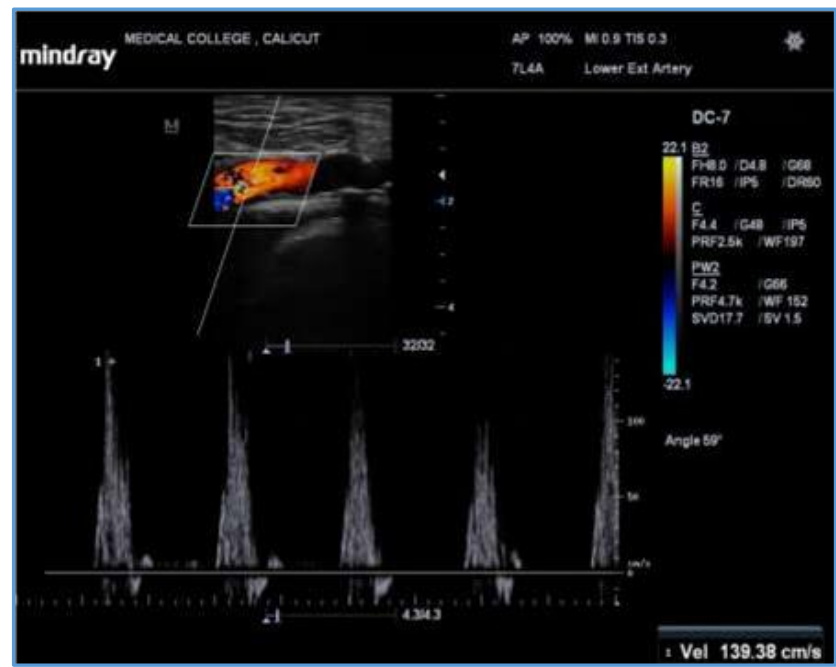

Fig. 6: Spectral Wave Pattern Increased Peak Systolic Velocity Proximal to the Occlusion
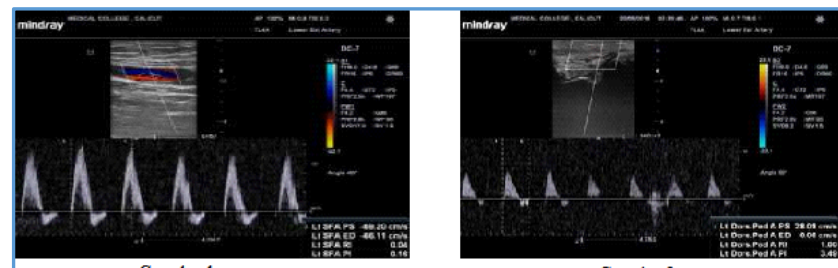

Grade

Grade 2

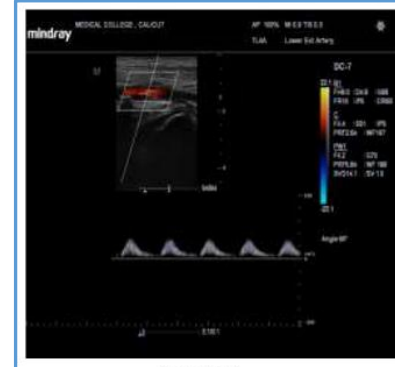

Grade 3

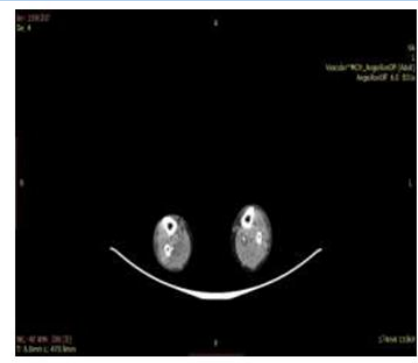

Grade 3: stenosis in MDCT Angiography
Fig. 7: Various Grades of Stenosis in Doppler USG 


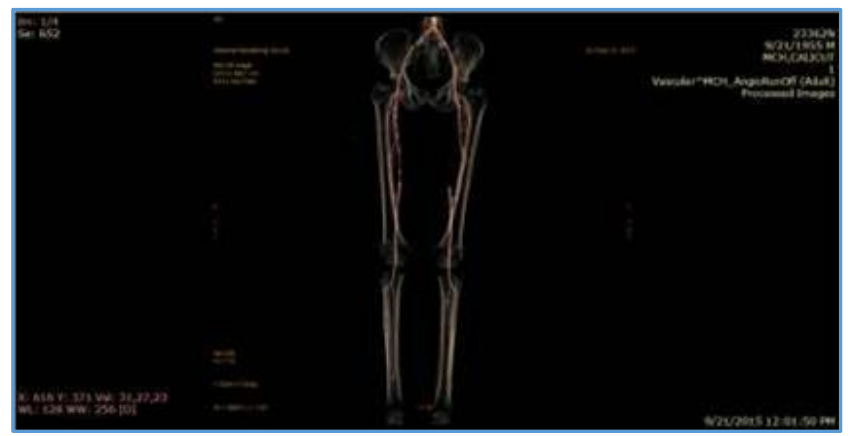

Fig. 8: Volume Rendered Image in MDCT Angiography

\section{REFERENCES}

1. Fowkes FG, Housley E, Cawood EH, et al. Edinburgh artery study: prevalence of asymptomatic and symptomatic peripheral arterial disease in the general population. Int J Epidemiol 1991;20(2):384-92.doi:10.1093/ije/20.2.384.

2. Kasper D, Fauci A, Hauser S, et al. Harrison's Principles of Internal Medicine. 19th edn. Vol. 1 and Vol. 2. McGraw-Hill Professional

2015. https://books.google.com/books?id=wNKVBgAAQBAJ\& pgis $=1$.

3. Khanna NN. Overview of peripheral vascular disease. Med Update 2005:89-99.

4. Abdulhannan P, Russell DA, Homer-Vanniasinkam S. Peripheral arterial disease: a literature review. Br Med Bull 2012;104(1):21-39.

5. Norgren L, Hiatt WR, Dormandy JA, et al. Inter-society consensus for the management of peripheral arterial disease (TASC II). J Vasc Surg 2007;45(1):S5-S67.
6. Zwiebel WJ, Pellerito JS. Introduction to vascular ultrasonography. $5^{\text {th }}$ edn. Philadelphia: Elsevier Saunders 2005.

https://books.google.co.in/books/about/Introduction_t o_Vascular_Ultrasonography.html?id=PQ1sAAAAMAAJ\& pgis $=1$.

7. Algazzar MAA, Elzawawi MSE, Alhawary KES. Role of multi-detector computed tomography angiography in the evaluation of lower limb ischaemia. Int J Med Imaging 2014;2(5):125-130.

8. Zierler RE, Zierler BK. Duplex sonography of lower extremity arteries. Semin ultrasound CT MR. 1997;18(1):39-56.

http://www.ncbi.nlm.nih.gov/pubmed/9143065.

9. Ouwendijk R, Kock MC, Visser K, et al. Interobserver agreement for the interpretation of contrast-enhanced 3D MR angiography and MDCT angiography in peripheral arterial disease. Am J Roentgenol 2005;185(5):1261-7.

10. Shirol RJ, Shetty A, Chethan TK. Role of MDCT in evaluation of peripheral vascular disease of the lower limb arteries and comparison with colour Doppler. J Evol Med Dent Sci 2015;4(54):9336-46.

11. Cossman DV, Ellison JE, Wagner WH, et al. Comparison of contrast arteriography to arterial mapping with colour flow duplex imaging in the lower extremities. J Vasc Surg 1989;10(5):522-9.

http://www.ncbi.nlm.nih.gov/pubmed/2681841.

12. Kayhan A, Palabiyik F, Serinsoz S, et al. Multidetector CT angiography versus arterial duplex USG in diagnosis of mild lower extremity peripheral arterial disease. Is multidetector CT a valuable screening tool? Eur J Radiol 2012;81(3):542-6. 